\title{
Desmedicalización de la experiencia de dolor en mujeres: usos de plataformas virtuales y procesos de agenciamiento subjetivo*
}

\author{
Demedicalization of the Experience of Pain in Women: Uses of \\ Virtual Platforms and Subjective Agencement Processes
}

Recibido: 24 de octubre de 2014 | Aceptado: 18 de Julio de 2015

\author{
PAtricia Amigot ** \\ Universidad Pública de Navarra, España \\ Margot Pujal i Llombart**** \\ Universidad Autónoma de Barcelona, España
}

doi 10.11144/Javeriana.psy14-5.dedm

Para citar este artículo: Amigot, P., \& Pujal i Llombart, M. (2015). Desmedicalización de la experiencia de dolor en mujeres: usos de plataformas virtuales y procesos de agenciamiento subjetivo. Universitas Psychologica, 14(5), 1551-1568. http:// dx.doi.or./10.11144/Javeriana.upsy14-5.dedm

* Artículo de investigación. Este estudio se apoya en la investigación "Les veus silenciades en temps "d'igualtat". El dolor des d'una perspectiva de gènere", coordinado por X y parcialmente financiado, en convocatoria competitiva Ref. U-27/10 (2010-2011), por el Institut Català de les Dones del Gobierno de la Generalitat de Catalunya..

** Doctora y Profesora de Psicología Social del Departamento de Trabajo Social. Correo electrónico: Patricia.amigot@unavarra.es.

**** Doctora y Profesora Titular de Psicología Social Departamento de Psicología Social. Correo electrónico:margot.pujal@uab.cat.

\section{RESUMEN}

El objetivo del artículo es analizar el uso de las plataformas virtuales por parte de personas afectadas por un dolor crónico sin causa orgánica. Se trata de un malestar emergente, creciente y controvertido en sociedades globalizadas, tecnologizadas y occidentalizadas, que afecta a mujeres en una ratio de 20/1 y que ha sido incluido en la categoría clínica de fibromialgia. Se parte de los estudios sobre el biopoder, la medicalización de la experiencia y del enfoque de género en salud, para desde allí analizar las posibilidades y límites de las plataformas en línea que facilitan procesos de agenciamiento subjetivo y transformaciones corporales, subjetivas, sociales y políticas significativas. La aproximación metodológica es cualitativa y la fuente de datos la constituyen los intercambios en cuatro blogs o foros en línea. Los resultados y la discusión final abordan la recuperación de las mujeres y la posterior simbolización de su experiencia conflictiva en los foros, así como los alcances y límites en términos de agenciamiento.

\section{Palabras Clave}

agenciamiento; plataforma virtual; perspectiva de género; medicalización; biopoder; análisis del discurso; fibromialgia

\section{A B S T R A C T}

The aim of this paper is to analyse the use of online platforms of people affected by chronic pain without organic cause. This is an emergent and growing malaise in globalized, technologized, western societies, that affects women in $90 \%$ of the cases). This malaise has been captured on the clinical category of fibromialgia. The study begins in the studies of biopower and the medicalization of experience, and the gender perspective in health. We ask if online platforms are sufficient to facilitate subjective agencement processes, that make possible a significant corporal, subjective, social and political transformation. We do this from a qualitative methodological approach. Our data source are the interactions in four different blogs and online forums. The results and discussions tackle the recovery and later symbolization of the conflictive experience in the forums, as its reach and limits regarding agencement processes.

Keywords

agencement; online platform; gender perspective; medicalization; biopower; discourse analysis; fibromyalgia 


\section{Desmedicalización de la experiencia de dolor en mujeres: usos de plataformas virtuales y procesos de agenciamiento subjetivo}

\section{Introducción}

En las últimas décadas, las sociedades contemporáneas capitalistas y tecnológicamente desarrolladas han aumentado de manera exponencial su demanda social de atención médica (Luz, 2011). Una de las razones es el aumento de las condiciones sociales, culturales y de poder adversas a la vida, que hoy en día caracterizan el mundo urbano, globalizado y neoliberal. Nos referimos a violencias simbólicas y estructurales en un sentido amplio y a la precarización de los vínculos, ejemplo de lo cual son la organización globalizada del trabajo y su desregulación o las distintas y renovadas formas de violencia de género que conforman el orden neoliberal actual (De Vogli, 2011). Uno de estos procesos ha sido referido como medicalización de la experiencia y presenta una tendencia al crecimiento exponencial de lo que la biomedicina puede abarcar. La biomedicina captura la experiencia y la vacía de su sentido subjetivo, cultural, social y político (Barker, 2005).

Dichas violencias simbólicas y estructurales afectan al conjunto de la población, pero con mayor intensidad a los grupos más vulnerables, donde confluyen diversos ejes de poder y desigualdad (De Vogli, 2011). Uno de estos grupos lo constituyen las mujeres, como efecto de la articulación del neoliberalismo con otras estructuras de poder, como el neopatriarcado, el neoracismo y la matriz heterosexual.

Uno de los malestares que ha crecido exponencialmente y que ha aumentado la demanda de consulta médica por parte de mujeres ha sido el dolor crónico sin causa orgánica, conocido clínicamente como fibromialgia ${ }^{1}$ (FM). La FM afecta con

1 Según la OMS (1994) la FM es un síndrome caracterizado por un dolor difuso no articular que afecta a los músculos y que se asocia típicamente con fatiga crónica persistente, sueño no reparador y rigidez generalizada. Está acompañado frecuentemente por otros síntomas corporales y psicológicos. Los criterios necesarios para el diagnóstico son: existencia de dolor difuso presente - como mínimo durante 3 meses_- la palpación dolorosa en 11 de los 18 un ratio desigual mujer/hombre de 20/1 (Ubago, Ruiz, Bermejo, de Labry, \& Plaza, 2005). Se trata de un malestar o síndrome emergente, controversial en la arena biomédica, social y jurídica, dada la imposibilidad actual de construir un protocolo consensuado que permita objetivar dicho dolor en los términos que el paradigma biomédico establece. Según Rivera (2009), la FM es en España la primera causa de consulta de mujeres en centros de atención primaria y de abandono de la actividad profesional, afectando a un 30\% de la población y resultando inhabilitante entre el $25 \%$ y el $50 \%$ de los casos. Las consecuencias más importantes de esta controversia son, por una parte, la falta de reconocimiento del malestar y de las personas que lo padecen, ya sea por un reconocimiento incierto de su dolencia o por falta de tratamiento adecuado - lo que puede conducir a su aislamiento, estigma o exclusión-y, por otra, un malestar o experiencia de burn out en los profesionales que atienden a estas personas, cuando no conflictos entre profesionales y saturación de las consultas de los servicios de salud estatal (Velasco et al., 2007).

Sin embargo, es cada vez más frecuente que dicha indefensión y estigma se gestionen a través de procesos de agenciamiento por parte de las personas afectadas, mediante la creación propia de organizaciones de pacientes ${ }^{2}$ o la creación de plataformas en línea, la mayoría ajenas a la organización de la sanidad estatal o pública. El objetivo de este artículo es problematizar, mediante un análisis del uso de la interacción virtual y discursiva entre mujeres afectadas y diagnosticadas clínicamente con FM, la medicalización de este malestar y la patologización de dicha problemática psicosocial. Para ello, partimos de algunos estudios sobre el biopoder, que lo entienden como "el conjunto de mecanismos por medio de los cuales aquello que, en la especie humana, constituye sus rasgos biológicos fundamentales podrá ser parte de una política, una estrategia política, una estra-

puntos sensibles posibles y la exclusión de alteraciones analíticas y radiográficas.

2 En Cataluña, en los últimos años, la lista de asociaciones de pacientes de FM ha crecido considerablemente, según lo constatado en nuestra investigación precedente. 
tegia general del poder" (Foucault, 2007, p. 15). Se parte igualmente de un enfoque psicosocial y de género en salud (Velasco et al., 2007), desde el cual el disciplinamiento normativo de las identidades de género constituye un dispositivo de poder que tiene un impacto diferente y desigual sobre la salud, el padecimiento y la calidad de vida de mujeres y de hombres.

\section{Una perspectiva de género}

para comprender el dolor

El concepto de sistema sexo/género desarrollado por Rubin (1986) es considerado aquí central para el análisis de la FM. Ampliamos la conceptualización de Rubin para entenderlo como un dispositivo de poder, desde una perspectiva foucaultiana (Pujal \& Amigot, 2010). En términos más concretos, articulamos dicho concepto con la perspectiva de género en salud siguiendo a Velasco (2009), quien define al sujeto que enferma como un sistema dinámico biopsicosocial generizado, es decir, como un sistema sujeto/sexo/género.

Desde esta perspectiva y a partir de Mora (2005), consideramos que la organización sexista de la vida social genera unas fuentes específicas de vulnerabilidad y fragilidad diferenciadas según el sexo y el género. Tres son las características fundamentales de una organización sexista occidental: la división sexual del trabajo; la construcción imaginaria, simbólica y material de las subjetividades de género, y las relaciones sociales mediatizadas por esta categoría. Sin embargo, hay variaciones en las combinaciones de estas características, lo que ha dado lugar a distintos modelos sociales de género en las sociedades globales occidentalizadas - entre ellas, España-. En la actualidad, conviven cuatro modelos sociales de género que pertenecen a distintas generaciones y son a la vez coetáneos por herencia social: tradicional, en transición, contemporáneo e igualitario (Velasco, 2009).

En esta línea, partimos de los resultados obtenidos en una investigación cualitativa sobre relatos de vida de mujeres diagnosticadas con FM (Pujal \& Mora, 2013, 2014), en la que el género aparece claramente como un determinante psicosocial y de biopoder de la FM, en el marco de un modelo social de género en transición al que se acogían las personas afectadas, que interactuaba con un modelo social de género tradicional al que pertenecían sus familias de origen. Dicho estudio muestra una clara influencia de ambos modelos. Estos, al interactuar con otros vectores de desigualdad —desde una perspectiva teórica interseccional- como la clase social, la migración, el modelo cultural, el estatus profesional, la edad y la posición subjetiva, entre otros, producían un yo generizado más normativo —y, por tanto, más precarizado— en comparación con otras mujeres. A partir de los resultados obtenidos en la investigación previa, nos preguntamos si las plataformas online, donde interactúan personas diagnosticadas clínicamente con FM, potencian — y en qué grado- procesos de agenciamiento y empoderamiento subjetivo. En otras palabras, la cuestión es si los procesos que tienen lugar en estas plataformas logran efectuar un tránsito desde una posición normativa de género subalterna (Spivak, 2003) hacia una posición de mayor agencia y si tienen un impacto en la vivencia del dolor corporal y del malestar subjetivo.

El empoderamiento, en este caso, se refiere al proceso por el cual las mujeres mejoran el control de los recursos materiales y simbólicos y refuerzan sus capacidades y protagonismo en todos los ámbitos, para convertirse en las protagonistas de sus propias vidas (Lagarde, 2005). Asimismo, el empoderamiento tiene una dimensión individual, relacionada con los propios niveles de autoestima y autonomía, y otra colectiva, relacionada con la necesidad de unirse con otras personas con el fin de aumentar la capacidad de participación e intervención en lo público - en tanto espacio de lo común-. Ambas dimensiones están relacionadas entre sí.

En definitiva, siguiendo a Michel Foucault y como hemos señalado en otro lugar (Amigot, 2005), los discursos y las prácticas sociales configuran, de una forma que varía históricamente, diferentes formas de autoconciencia y reflexividad. Esto es un efecto de las relaciones de poder que opera constantemente, incluso sin que seamos conscientes de ello, dado que la subjetividad es un proceso abierto y no completamente transparente. El lenguaje se 
abre a diversos usos, a desplazamientos y fracturas en los sentidos.

\section{Estudios sobre los efectos de bienestar de la interlocución virtual}

Internet se ha convertido en un poderoso escenario de información e interacción global en relación con la experiencia de enfermedades y malestares contemporáneos. La búsqueda de información no es lo único que motiva el acceso a la red: la dimensión experiencial y subjetiva de la enfermedad aparece como un nudo que se estructura narrativa y dialógicamente en el contacto virtual, como objeto de exposición, de síntesis, de ejemplo y de palabra, dirigida a quien pueda comprenderla porque padece la misma situación.

Este contacto intersubjetivo en línea permite compartir experiencias, tanto en una dimensión expresiva - de exposición emocional- como instrumental — de elaboración de estrategias de afrontamiento y de prácticas de agenciamiento y autocuidado- . Tal como señalan Walther y Parks (2002), Internet es un medio fabuloso para el apoyo social. Escribir y entablar un diálogo virtual son prácticas que tienen efectos. El lenguaje, en términos de Wittgenstein (1969), soporta diferentes usos además del descriptivo - habría otros usos entrelazados con este, a los que él denomina juegos de lenguaje, que son e implican formas de vida distintas-. Una de las líneas de investigación más importantes en relación con los foros virtuales de personas aquejadas por un problema de salud es la que analiza el efecto beneficioso de la participación, asociada al tipo de expresión emocional y subjetiva que permiten (Pennebaker \& Graybeal, 2001; Suriá $\&$ Beléndez, 2009). Los dos mecanismos más relevantes en la consecución de ese efecto beneficioso son, por un lado, la autorrevelación, que permite dar sentido al pasado a través de la ordenación de las experiencias y, por otro, la reestructuración simbólica, que señala la posibilidad de expresión de emociones positivas y la disminución de las negativas. En este sentido y en el caso de la FM, la expresión de rabia o ira - unas de las emociones más reguladas en la socialización normativa de la feminidad_ puede ser beneficiosa y apuntar a un proceso de resignificación y transformación subjetiva.

Los sentimientos tienen una dimensión política, en el sentido de que las relaciones de poder regulan, de alguna manera, los objetos legítimos de determinadas emociones. Los sentimientos negativos suelen desviarse hacia abajo, mientras que los positivos "suelen subir la cuesta sociopolítica" (Hochschild, 2008, p. 126). Esto implica que los grupos sociales con menor poder tienen una menor posibilidad de expresar su enojo y que son objeto de este con mayor frecuencia.

\section{Método y materiales}

La aproximación metodológica del estudio fue cualitativa y constó de dos procedimientos: la producción de datos y el análisis de los mismos. Las fuentes de datos fueron el seguimiento, desde diciembre de 2010 a mayo de 2011, de los intercambios virtuales en cuatro foros sobre fibromialgia: Fibromialgia Noticias, Fibroamigosunidos, Blog de El País y Fibroamigos. Seleccionamos distintos diálogos, según criterios de muestreo teórico, para poder obtener mayor variabilidad de opiniones y puntos de vista en la muestra. En todos ellos, las impulsoras fueron personas afectadas - no profesionales de la salud-. Dos de los foros fueron creados directamente por personas afectadas; los otros dos, por colectivos que, además, realizan encuentros no virtuales — aunque son poco habituales-, como la Asociación Civil sin fines de lucro que difunde conocimiento sobre FM y el Colectivo Online de FM, un grupo de apoyo y reivindicación.

El objetivo del análisis fue comprender la perspectiva que tienen las personas informantes sobre sus vidas, experiencias y situaciones, así como el sentido que atribuyen a sus actos (Taylor \& Bogdan, 2000).

En cuanto a las técnicas de análisis de datos, usamos el análisis de contenido y el análisis crítico del discurso. El primero pretende organizar la información con base en las categorías que emergen de la interpretación de los datos. El programa ATLAS-ti 6.0 fue la herramienta que nos permitió trabajar con la información y crear categorías. En este proceso de 
análisis hubo dos fases diferenciadas: el nivel textual - la creación de citas y códigos- y el nivel conceptual — la elaboración del análisis que relaciona conceptualmente las citas y los códigos-. En cuanto al análisis crítico del discurso, lo entendemos como una técnica analítica que localiza relaciones de poder entre posiciones determinadas (Iñiguez, 2003). Esta línea concibe el discurso como una práctica social, lo que cuestiona su consideración como práctica descriptiva o representativa (Potter \& Wetherell, 1987).

Estas técnicas nos permitieron sistematizar todas las intervenciones: el análisis de contenido nos permitió categorizarlas, mientras que el análisis del discurso permitió establecer relaciones entre las categorías, realizar un análisis semántico y uno teórico-interpretativo, atendiendo a la dimensión pragmática y a los efectos políticos de los textos.

\section{Análisis de los resultados: del dolor de las palabras a las palabras de dolor}

Los resultados del análisis, en relación con el sentido narrativo y dialógico de los intercambios, se organizaron en tres ejes cualitativos y en una progresión narrativa de estos. Cada uno de los ejes es explicado teóricamente e ilustrado a través de algún intercambio virtual.

\section{Dolor y búsqueda de sentido}

Las perspectivas discursivas de la psicología social actual subrayan el efecto performativo del lenguaje: más que una representación de una realidad existente, el lenguaje configura esa propia realidad mediante su descripción (Ibáñez, 2003). Ello no significa que no exista aquello a lo que aludimos, sino que su comprensión pasa por su configuración narrativa, puesto que la materialidad no habla por sí sola: siempre hay una discontinuidad entre lo existente y la configuración que adquiere en nuestras palabras.

Una de las funciones más importantes que tienen los foros virtuales en relación con esta dolencia es recibir e intercambiar el malestar y el estupor que la sospecha y duda acerca de la enfermedad generan en la vivencia de la misma. Dolor e intersubjetividad están estrechamente vinculados y esto tiene dos consecuencias importantes: por un lado, el hecho de que la construcción de significados sea un proceso psicosocial —en el que los significados se negocian de manera intersubjetiva (Crespo, 1995) _ implica que, cuando un otro social niega, implícita o explícitamente, una experiencia, se crea un vacío que difícilmente puede llenar de contenido por sí mismo — no sin una profunda inquietud por la inestabilidad de sentido que provoca el no reconocimiento- - Por otro lado, la profunda imbricación entre dolor y subjetividad implica que el descrédito del primero sea simultáneamente un descrédito personal que provoca más dolor. Veremos a continuación estas consecuencias, generadas por la limitación de la narrativa biomédica en los pacientes.

\section{El dolor que no existe o la limitación de la narrativa biomédica frente al dolor vital de las mujeres}

Cuando el dolor no se entiende como síntoma de la experiencia subjetiva de la persona — síntoma multidimensional-, el dolor que no encuentra causa orgánica es condenado a una permanente sospecha sobre su existencia real y genera un dolor añadido enorme en las personas que lo padecen: son confrontadas y autoconfrontadas constantemente con un vacío de sentido y con un enigma que desgarra su propio sentido de sí. Cuando el dolor bordea la irrealidad, a causa de su no localización y de su falta de comprobación experta, la propia experiencia adquiere una terrible ambivalencia entre el sufrimiento que invade lo subjetivo y la no comprensión, transmisibilidad y reconocimiento de esa experiencia. "Para muchos médicos solo somos locas e histéricas, y quizás tengan razón $(\mathrm{BF} 1,44)^{3}$.

La irrupción del dolor en la vida de la persona se convierte así en un doble dolor, dada la dificultad de

3 Las iniciales se corresponden de la siguiente manera con los foros: Blog de El País sobre Fibroamialgia (BF1); Blog Fibromialgia Noticias (BF2); Blog Fibromialgicosunidos (BF3); Blog Fibroamigos (BF4). 
situarlo simbólicamente y de (auto)reconocerlo intersubjetivamente. La búsqueda de reconocimiento personal, que probablemente ha acompañado a estas mujeres a lo largo de su vida, se hace imposible en circunstancias psicosociales marcadas por el dispositivo de poder de género y otros factores (Llombart \& Mora, 2013). La experiencia de dolor corporal, inhabilitadora y extrema, pide ser reconocida al tiempo que queda bajo sospecha: sospecha del médico, sospecha de los otros, sospecha de los próximos acerca de la verdad de ese dolor. Este descrédito opera en la práctica como un descrédito personal, puesto que la experiencia corporal es escuchada con reticencias.

Y mientras, si dices que tienes fibromialgia, ya notas cómo te miran. No te creen... en fin. Parece que pierdes valor como persona y eres más bien poca cosa como para que te escuchen... ni siquiera familia o amigos. Yo me puedo pasar hasta diez días sin hablar con nadie, salvo el panadero o el de la tienda o supermercado. Qué fuerte. (BF2, 314)

En sus palabras, esto parece provocar tanto dolor como el físico. Hay un desplazamiento: de lo inaguantable de la enfermedad a lo inaguantable de la falta de comprensión. El dolor aparece por la respuesta de los otros: "Yo la tengo hace muchos años y no se puede aguantar, no te comprende la gente (BF1, 30). "Me duele mucho que muchas veces mis propios hijos me ven como si estoy exagerando en mis malestares y dolores" (BF2, 351).

En esta otra cita aparece la misma duplicación del dolor, pero no tanto por la incomprensión sino por la sanción que encuentra al no poder desempeñar ya los roles que le corresponden, en este caso, vinculados al cuidado de otros y a la identidad de género femenina: "No solo es dolor físico, es dolor del alma, cuando te ves casi abandonada por todos, porque ya no eres productiva, no puedes cuidar nietos, y un largo etc." (BF2, 316).

La alusión al dolor del alma se repite en relación con la incomprensión: "Gracias por tus palabras (...) tengo pérdida de memoria, desconcentración, hay días que no puedo levantarme de dolores de huesos y lumbago, nadie lo entiende, mi enfermedad es del alma" (BF2, 361).
Esto tiene su contrapartida en el efecto que produce el diagnóstico. Esta última palabra provoca alegría, tranquilidad y apaciguamiento del malestar que el no reconocimiento de los otros genera. El diagnóstico opera como el fin de un deambular estresante por el dispositivo médico, pero, sobre todo, aparece como la consecución de un espacio y posición simbólicas que contienen, en parte, el (auto)cuestionamiento.

Podría decirse, incluso, que se evidencia un cierto deseo de diagnóstico de fibromialgia:

Y aun así no puedo con mi cuerpo. Me pasan cosas raras y dolores raros (o eso dice la gente) y por eso me da vergüenza ir al médico. A lo mejor son simples coincidencias sin más, pero yo creo (o quizás "me gustaría”) tener fibromialgia, porque así podría dar una justificación a todo lo que me pasa y demostraría a la gente que no soy una vaga ni una histérica que se pasa el día quejándose. $(\mathrm{BF} 1,26)$

El efecto del diagnóstico es recibido, en general, como un enorme alivio dentro de la situación de experiencia de dolor y cansancio, incluso cuando supone el reconocimiento de una enfermedad crónica. Así las cosas, la recepción del diagnóstico es ambivalente.

Después de muchas pruebas, ya me han diagnosticado de fibromialgia. Y bueno, estoy dentro de una contradicción: por una parte contenta, porque me confirman que no estoy "loca", pero por otra, me está costando asimilarlo porque, si miras al futuro, lo que nos espera es dolor y más dolor. (BF1, 42)

Es interesante cómo ese peregrinar agotador en busca de una respuesta es entendido por los pacientes como un martirio, que se acaba cuando se encuentra un nombre para el dolor, reconocido ahora por el dispositivo médico: "Hola M., sabes que después de hacerme todos los exámenes habidos y por haber, fui a una nutricionista para hablar de eso y sabes, ella me descubrió que tenía fibromialgia, fui por una cosa y me descubren otra. Terminé con el martirio" (BF1, 48). También lo atestiguan así, otras intervenciones similares: "Terminé con el martirio 
de no saber por qué tanto dolor en mi cuello, brazos y piernas, qué cosas, ino?" (BF1, 49). "Qué bueno es saber al fin lo que tienes, que no es mentira, ni hipocondría, ni flojera, ni histeria ni histrionismo, ni teatro" (BF2: 239).

Incluso pareciera que, a partir del reconocimiento, se mitigara el dolor físico: "Entonces me dijo, espera, tienes fibromialgia. Me recetó Lyrica y Lexapro. Y al otro día quería que todo el mundo supiera lo buena que es mi doctora, porque a pesar de que el dolor no cesó totalmente, ya no dolía al punto de la incapacidad" (BF2, 74).

Esta reacción también es provocada por las conversaciones que tienen lugar en el foro. El reconocimiento alivia el dolor y opera como un otro que disipa dudas acerca de la 'verdad': "He llorado al leerla, me sentí comprendida, que no era mi mente la que me traicionaba inventando dolores "imaginarios", veo que padecemos todas lo mismo, aunque no seamos comprendidas por los "sanos". (BF2, 355)

\section{Un sentido que resiste la psicopatologización}

El vértigo ante la falta de sentido, provocado por el no-reconocimiento y asociado, a su vez, a la perspectiva dualista mente/cuerpo, hace que la reflexión acerca de la experiencia subjetiva del dolor tienda a abrir espacio a la consideración de la locura. Tal como hemos comentado, cuando el dolor no tiene base orgánica, tiende a ser psicopatologizado, lo que implica, convencionalmente, un descrédito del mismo en tanto imaginario o inventado, así como un (auto)descrédito de la persona, en tanto 'loca', histérica, mentirosa o incluso, vaga y perezosa. Cuando la persona no logra salir de esa narrativa, la única esperanza es el descubrimiento médico de los procesos patógenos. Esto se refleja en la siguiente cita, que caracteriza a la enfermedad como fantasma, metáfora que refleja el complejo estatuto médico que tiene esta enfermedad. La dificultad a la que se enfrentan los pacientes con fibromialgia es, en ocasiones, mayor que aquella que afrontan los pacientes con cáncer, por tratarse esta última de una enfermedad socialmente reconocida en su gravedad.
"Yo pasé por un cáncer y, aunque fue muy duro, difícil y lastimó mucho mi cuerpo, puedo decir que la fibromialgia es (para mí) más terrible aún, es un fantasma contra el que no puedo luchar, es algo que me vino a quitar mucho" (BF4, 27).

\section{Vivir duele. Un saber no-} experto compartido.

El lenguaje de los expertos opera desde una posición socialmente autorizada para decir el significado último de las cosas. En una sociedad en la que los dispositivos científicos se han erigido como portavoces indiscutibles de la verdad, el saber experto es designado para perfilar la verdad de la enfermedad (Velasco, 2009). En los foros, las experiencias de los recorridos médicos aparecen fundamentalmente como una queja frente a la incomprensión, como reproche hacia la ignorancia de la medicina, como reconocimiento a las buenas prácticas y profesionales e, incluso, como esperanza en relación con la investigación y el descubrimiento de una solución.

Por lo tanto, el 'no-saber' biomédico incita a una elaboración conjunta del sentido del dolor. Una de las claves del diálogo es el reconocimiento otorgado mutuamente: la experiencia de dolor es reconocida por las otras personas y la 'verdad' del relato no es cuestionada ni reinterpretada por otros. En consecuencia, la demanda reiterada de reconocimiento y el silencio victimista en el que se refugian las pacientes no-reconocidas pueden ser aliviados en los foros. La alusión al silencio es hecha por algunas personas que intervienen por primera vez y se refiere, sobre todo, a la incomprensión en el ámbito familiar y más próximo. La incomprensión por parte del entorno lleva al encierro en una misma y, en esas circunstancias, las posibilidades de recibir apoyo, de resignificar la vida y de establecer estrategias de autocuidado descienden drásticamente.

A veces no aparece el silencio sino la falta de aceptación. En ambos casos, otras intervenciones se ofrecen como consuelo y consejo.

No hablo nunca de fibromialgia. Doce años con ella ya está pudiendo conmigo. Información tengo tanta como tratamientos he llevado. (...) me veo 
demasiado reflejada en vuestras experiencias. No sé si es bueno o no leeros, puesto lo que he hecho hasta ahora ha sido ponerme una venda en los ojos para evitar el tema con todo el mundo. (BF4, 24)

La respuesta:

$\mathrm{X}$ cielo, es que no aceptas la enfermedad, por eso no quieres verla, cariño, somos muchas y luchando mucho porque no podemos quedarnos así sin más, tienes que aceptarla, para poder ver con tus ojos que no estás sola y, si te abres a la realidad, te verás más comprendida y apoyada. $(\mathrm{BF} 2,88)$

La identificación mutua en términos de enfermedad permite, en primer lugar, sentir el apoyo y la solidaridad y, en segundo, que las palabras e interpretaciones de las otras personas sean clave para nombrar la propia experiencia y resignificarla. Este reconocimiento e identificación mutuos permiten que la experiencia supere, mediante su expresión, la insistencia en los síntomas y sea contextualizada e historizada. Ello tiene el efecto de integrar ese cuerpo doliente en una narrativa vital, superando, de facto, la dicotomía mente/cuerpo.

El reconocimiento mutuo parte, primero, de un reconocimiento del cuerpo doliente, que es integrado en la experiencia relatada. No obstante, en las representaciones del cuerpo y de la enfermedad aparece una tensión: entre el cuerpo objetivado, ajeno a la experiencia subjetiva, y el cuerpo integrado - en el sentido de una misma y del proceso vital-.

La emergencia de un saber acerca de la vida y de sus circunstancias aparece como una luz de la que otros - los que no entienden - no tienen idea. Aquí, el dolor tiene una profundidad vital, desde una perspectiva integrada y no dicotómica, y es compañero del proceso de existencia. En la primera cita, por ejemplo, el dolor acompaña a la vida solo de un "nosotros pacientes", pero en la segunda, el dolor se considera consustancial a toda vida, aunque la enfermedad otorga una especial lucidez ante ello.

"Es cierto que para nosotros vivir duele y eso difícilmente se puede entender, por lo que parece" $(\mathrm{BF} 3,38)$. "En nosotros se cumple la máxima de que vivir duele y aun así somos capaces de adaptarnos" $(\mathrm{BF} 2,18)$. "Con la fibromialgia 'duele la vida', y de paso el alma, el dolor llega al corazón” (BF2, 78).

Al partir del reconocimiento, los foros virtuales proveen narrativas y palabras para articular una experiencia más compleja y fracturar identificaciones rígidas con la enfermedad. "Jamás he podido explicar con palabras todo lo que sentía, ya que solo podía decir dolor, esa es la palabra que me definía como persona" (BF2, 64).

\section{Metáforas: la reconfiguración de la} vivencia. La enfermedad y la batalla

El recurso lingüístico a la metáfora como modo de expresividad implica la acción de un hablante que va más allá de las estrategias representacionales: no solo denota una realidad, sino que abre el mundo y detecta algún aspecto inaccesible para el lenguaje ordinario. Las metáforas son innovaciones semánticas, creaciones de sentido que revelan nuevos valores de la realidad (Ricoeur, 2001). Abunda, en los foros, el recurso a metáforas sociales que representan el sufrimiento: la 'cruz', el 'calvario' y el 'infierno'. También aparecen las figuras de la 'losa' — algo que se debe arrastrar-y de la 'cárcel', donde la condena es el dolor, tal y como puede observarse en esta línea de diálogo en el Blog de Fibromialgia Noticias: "Hola a todas-os, yo la sufro ya hace siete años y es un calvario" (BF1, 58). "La losa que te pesa [con] nada más levantarte” (BF2, 12). "Lamentablemente, nos correspondió cargar esta cruz" (BF2, 33). "Mis mejores deseos desde esta cárcel de dolor" (BF2, 121).

Algunas mujeres incluyen una dimensión subjetiva en la metáfora y no figura el dolor como una condena que hay que afrontar. Este aparece representando, en términos subjetivos y de género, como un ser roto: "Somos muñecas rotas" $(\mathrm{BF} 1,3)$.

La enfermedad aparece referida, generalmente, de tres maneras: como una ruptura — lo que subraya el punto de inflexión, un antes y un después—; como una pérdida, y como una batalla —la expresión más recurrente para referirse a la enfermedad-. Una batalla es una situación estratégica en la que nada está decidido: siempre hay un costo, pero el resultado 
puede llegar a ser satisfactorio. La enfermedad como batalla supone la vivencia permanente de una situación de lucha. Esto tiene varias consecuencias: por un lado, la experiencia de la enfermedad se entiende como un proceso. Lejos de la vivencia de una prisión estática o de una condena permanente, una lucha presupone la capacidad de operar sobre la situación y la posibilidad, esperanza o certeza de que ese actuar podrá tener pequeñas recompensas.

La referencia a la lucha suele estar relacionada con la elaboración colectiva de estrategias para afrontar las dificultades del dolor y con la expresión de una autovaloración que infunde ánimos. "Esto es una lucha más, que nos deja inactivas durante unos días pero que luego nos permite continuar. Sobre todo, no os quedéis inactivas, el día que podáis salir, hacedlo y procurad tener siempre la mente ocupada, haced yoga, tai-chi, bolillos, ganchillo" (BF1, 24).

\section{La expresión de tensión emocional}

La expresión de emociones es muy importante en la interacción virtual. Entre ellas, destacamos dos tipos:

a) Tensión emocional entre vergüenza y orgullo. La vergüenza está muy relacionada con la 'locura' o la experiencia de un dolor que "en realidad" no existe. Frente a esta, hay muchos mensajes que insisten en situar el problema en algo externo y no en la persona que sufre, apuntando a transformar la vergüenza en orgullo, dado por el heroísmo que implica el padecimiento:

Lo que sí les digo es nunca se avergüencen con su médico, familia o amigos, si ellos no lo entienden traten de educarlos y si no lo logran, al diablo, tienen que ir con toda firmeza y seguridad a su médico, y si no los entiende, luchen y busquen otro que sí lo haga, aunque sea una gran búsqueda. (BF2, 260)

b) Tensión emocional entre tristeza, rabia y culpa. En algunos casos, la rabia parece convertirse en resignación y depresión, en las mismas situaciones en las que otras personas manifiestan enfado o ira. La rabia emerge ambivalentemente cuando el noreconocimiento deja de ser inhabilitador y se lee como un agravio externo. No obstante, en varias intervenciones aparecen expresiones paradójicas en relación con la identificación de ese agravio o maltrato. Aparece igualmente la necesidad de asumirlo humildemente, con miedo a una reacción legítima, conflictiva y, probablemente, inútil: "Aceptando humildemente, porque lo contrario es ir contracorriente... es enfermar del alma... es darle paso a la rabia... a la oscuridad" (BF2, 15).

La expresión de tristeza y depresión está vinculada a la percepción de la enfermedad como una pérdida. En algunos casos, se alude incluso al duelo que genera su aceptación:

Hola, soy nueva en esta bella casita, espero ser bienvenida, gracias por recibirme... estaba tan deprimida que entré a buscar información positiva después de reconfirmar lo que me negaba más de mil veces en aceptar, que tengo fibromialgia, como si el desearlo con todas las fuerzas iba a lograr que se hubieran equivocado en el diagnóstico... pero ya estoy aun en el proceso de luto. $(\mathrm{BF} 4,3)$

La culpa no aparece explícitamente, pero podemos inferirla de algunos testimonios que aluden al dolor que supone la limitación física, que impide ocuparse de hijos e hijas pequeñas. Son situaciones en las que la posición de género femenina de "ser para otros" emerge claramente:

Aun cuando muestre mi mejor sonrisa por dentro estoy sintiendo que las fuerzas se desvanecen y las fuerzas se me agotan... y ya no puedo más... pero a seguir para adelante, quiero salir de la prisión que yo misma me impuse, prisión donde guardo mis dolores, sentimientos que no permiten que entre nadie y que está a punto de explotar... por lo que me atreví a entrar aquí como una forma de catarsis, de desahogo donde nadie me mire, vea mis lágrimas y me sienta cobarde y culpable de no dar de mí todo lo que mi hijo quisiera. (BF2, 4)

No quiero amargar a mi familia. (BF2, 115)

De todas formas, en algunos testimonios no deja de ser significativo que determinados conflictos familiares aparezcan velados por la enfermedad. 
Los síntomas muestran su compleja etiología biopsicosocial (Velasco, 2009).

"Discutía con mi marido absolutamente por todo. La cría mayor solo tiene seis añitos, me decía que estaba triste y que siempre tenía ganas de llorar. A mí se me caía el mundo encima. Todo eran reflejos de mi enfermedad." (BF2, 132).

Esta posición resalta el efecto que la enfermedad tiene sobre la función materna y de cuidado de las mujeres afectadas. Los hijos generan culpa, pero son a la vez una motivación para salir adelante:

A veces quisiera dormirme y no despertar, pero aún mis hijas están pequeñas y es por ellas que me levanto cada mañana luchando con mi propio cuerpo, con mi alma, con el dolor. Como decía las abuelas, "no hay mal que dure 100 años ni cuerpo que lo resista". (BF2, 343)

Como plantea Rabeharisoa (2006), a través de los ejemplos anteriores podemos ver el surgimiento de una identidad colectiva compartida -identity claim-de naturaleza biosocial.

\section{Resignificación subjetiva}

Refiriéndonos a la emergencia de una bioidentidad compartida, consideramos la resignificación subjetiva - que tiene lugar a partir de la emergencia de la enfermedad y en el diálogo virtual — en tres sub-ejes que surgieron en el análisis.

\section{Resignificación colectiva: nosotr@s}

La intersubjetividad que se integra en los foros funciona como una fuente de identificación y, por tanto, de interpretaciones y recursos para articular la experiencia. La resignificación colectiva tiene una sólida base en la identidad que provee el diagnóstico y que genera definiciones en términos colectivos.

Consideramos los efectos de la categorización en términos de la enfermedad desde la teoría de la identidad social (Tajfel, 1978; Turner, 1987). La categorización, que cumple un papel definidor en la enfermedad, genera una clara distinción entre "los enfermos" y "los sanos", a la vez que amalgama a los primeros en un colectivo. Allí se reconocen porque son parecidas y se desatan lazos virtuales — pero no por ello menos intensos- de afecto y apoyo: "Sé que no estoy sola... estoy con cada uno de ustedes" (BF2, 325).

La configuración grupal, que parte de la mutua identificación y que está orientada elaborar significados identitarios colectivos, tiene su otra cara en la distinción entre un nosotras y los otros. Ello aparece reiteradamente en testimonios como este: "Veo que todas padecemos lo mismo, aunque no seamos comprendidas por los "sanos"” (BF2, 355).

Nos resulta extrañamente llamativo el hecho de que no se refieran más a menudo a su condición de mujeres, aunque en algunos momentos hablen en femenino. Que la enfermedad sea mayoritariamente femenina no es un hecho aludido de manera explícita en las intervenciones y en los diálogos. La que sigue es una excepción: "Solo puedo decir que ánimo, que no nos dejemos vencer, somos mujeres y estamos acostumbradas a luchar día a día” (BF1, 1.24).

Existe cierta tendencia a representar ese estado de unión colectiva en términos espaciales, lo que resulta llamativo tratándose de un medio virtual y anónimo - aunque el anonimato suela desdibujarse con la transmisión de las vivencias personales y detalles íntimos de la vida-. Las dos imágenes que aparecen ocasionalmente son, primero, la de un solo cuerpo, que contendría a todas las personas afectadas, $y$, segundo, la del foro como un lugar afectivo, como una "casita" en la que tienen cabida todas las mujeres que sufren. Allí, se cuidan unas a otras: "Una de las mejoras cosas que leí, me siento tan identificada, es tal cual, nos sentimos pero tenemos que seguir nuestras vidas por más que parezcan que somos muchos en un solo cuerpo" (BF2, 226). "Hola $\mathrm{C}$ cariño,... claro que eres bienvenida... ya verás como aquí encuentras una casa donde nos apoyamos entre tod@s" (BF4, 7).

Se aprecian también deslizamientos reiterados entre lo individual y lo colectivo: "Soy una luchadora y una superviviente de mi propio cuerpo, como todas vosotr@s!” (BF1, 47). 
Por otra parte, las presentaciones 'positivas' tienden a integrar la enfermedad a lo subjetivo, pero sin agotar su identidad en el hecho de estar enfermas: "Soy FM y un montón de líos más" $(\mathrm{BF} 1,5)$. "Soy activa, trabajo mucho, y tomo clases de salsa y canto en un coro polifónico... pero me tira abajo pasar por crisis en las que no puedo salir ni hablar por teléfono por los malestares" $(\mathrm{BF} 1,6)$.

\section{Autorizándose al discurso y a la práctica}

Una consecuencia de las relaciones de poder es la denegación de un criterio de interpretación y juicio. Por tanto, una táctica de resistencia a la posición subordinada consiste en afirmar el criterio alternativo que se maneja en la construcción de sentido. Esto implica una autorización — generalmente subrepticia - para saber algo que los demás no saben. $\mathrm{El}$ poder de las palabras no reside en las propias palabras, sino en los contextos que condicionan el alcance y los efectos de determinadas proposiciones (Bourdieu, 1982).

Podemos apreciar una fractura de la univocidad del lenguaje de la autoridad en el desconocimiento de la misma, así como en la percepción de sí mismos como sujetos de un saber que se legitima intersubjetivamente.

La percepción mayoritaria es que los médicos no saben mucho, lo que suscita reacciones emocionales diversas, que van desde la vergüenza hasta la rabia y el desprecio: "Qué malo saber que los mismos médicos sean tan ignorantes y que no sean capaces de reconocerla como una enfermedad invalidante" (BF2, 239).

Los saberes menores, clandestinos, oscuros pero compartidos, emergen como un elemento autorizado que otorga voz y permite profundizar la narración.

Es que les damos clase gratis, sí, a los médicos les damos clase gratis, les contamos nuestros síntomas, nuestros desasosiegos, todo lo que les pueda orientar para entender nuestra enfermedad, porque es así como van aprendiendo sobre la fibromialgia, con nuestras experiencias, con nuestro sufrir día a día. $(\mathrm{BF} 1,84)$
Esta posición de autorización le permite centrarse en sí misma y autorizarse en el cuidado:

Hoy en día me siento un poco mejor, ya que he dejado de preocuparme tanto y evito discutir, trato de llevar la vida con más calma, lo único que me preocupa es que, a pesar de todo esto, hay crisis y estas se presentan de diferente forma. (BF2, 150)

Antes nos decían que escuchemos al cuerpo, ahora no lo escucho, escucho mi corazón, me amo, me cuido con dieta sana, con mucha agua, frutas y verduras, hago tai chi, yoga, bici, camino, todo de acuerdo a lo que me aguanta el cuerpo, me relajo todos los días y descanso mucho. (BF2, 339)

\section{Valoración intersubjetiva frente a la fragilidad del reconocimiento}

Los foros son una fuente inagotable de reconocimiento: apaciguan la necesidad de ser creída y, por ello, pueden complejizar la expresión de la experiencia del dolor más allá de la demanda y de la queja. Además, se obtiene un reconocimiento en términos afectivos de valoración. Palabras y apelativos cariñosos saltan de mensaje en mensaje en estos casos. Se trata de toda una semántica del cuidado mutuo que se despliega como muestra de una solidaridad férrea: "Cielo, tú ánimo y pa'lante" (BF1, 35). "Un besito con todo mi cariño. Cuídate, preciosa” (BF3, 37).

Otro elemento que opera como fuente de (auto)valoración tiene que ver con la enfermedad como batalla y con la enferma como heroína tiene que soportar que no la crean, una medicina sin remedios, el propio dolor y agotamiento, etc-. Lo anterior conduce a una atribución de fortaleza a esas personas, cuya cotidianidad pasa siempre por la debilidad física. En otras palabras: son fuertes.

Vivimos una gran mentira, una mentira que lidiamos con una fortaleza insuperable, porque para nosotros, más que para nadie, vivir el día a día es prueba más que suficiente de una fortaleza casi sobrehumana. (BF1, 18) 
Vosotras sabéis lo que es sacar fuerzas de flaqueza para seguir cada día con nuestra actividad. Yo así lo hago diariamente, me despierto y lo primero que digo es "hoy ya no puedo más", pero casi literalmente me tiro de la cama, porque como me rezague, no me levanto. $(\mathrm{BF} 3,46)$

\section{Construcción dialógica de la agencia}

A partir de los ejes expuestos hasta el momento, destacamos ahora los elementos más significativos, por su potencial para resignificar la posición de enferma pasiva — producida por la mayoría de interpelaciones biomédicas y sociales- hacia una más activa y subjetivamente agente. Desde esta posición y más allá del dolor, las mujeres se perfilan con mayor densidad, complejidad emocional y capacidad de articular prácticas de autocuidado. Tal posición la caracterizamos como una subjetividad que rescata pequeñas hebras de agencia, que se entrelazan, a su vez, con las limitaciones que el malestar impone.

Esta configuración particular de la agencia contrasta con posiciones ancladas en la identificación con la enfermedad y con posiciones victimistas y reiterativas en su queja pero que no son las más habituales:

"Creo que es una de las peores enfermedades, pues no tienes nada clínicamente y pueden creer que haces tú cuento y no te aguantas el dolor. Espero que lo que acaben diciéndome sea que encuentran un medicamento que vuelva las ganas de vivir" (BF2, 111).

A continuación presentamos algunas narrativas, intervenciones e interacciones que se caracterizaron por una recuperación minuciosa de la agencia. Las ordenamos según cuatro ejes.

\section{Reapropiación del cuerpo, ruptura de la visión dualista}

La imaginarización del cuerpo podría, por un lado, dibujarlo como un elemento ajeno a un sí mismo
— que sostendría el verdadero sentido subjetivoo, por otro, ser integrado en ese proceso subjetivo, complejo y multidimensional. Las vivencias del cuerpo como 'cárcel', 'losa' o 'enemigo' ilustran esta imaginarización dicotómica y configuran un sujeto sometido a un discurso social que vincula la agencia a la capacidad de dominar y utilizar el cuerpo. En el caso de la enfermedad que afecta a un cuerpo situado así imaginariamente, esta agencia es mínima. Además, el sufrimiento tiene un profundo poso de rechazo de ese cuerpo que, a pesar de todo, es propio.

Sin embargo, el cuerpo puede ser integrado de maneras más complejas e inestables cuando una es su cuerpo y cuando aquello contra lo que se lucha es la enfermedad - no el cuerpo-; es decir, cuando la enfermedad es una batalla a la que se va con el cuerpo y no contra él. Hemos señalado diversas intervenciones en las que se expresa la necesidad de cambiar de actitud hacia una misma y de cuidarse. Este cuidarse implica cuidar, simultáneamente, el cuerpo. Es especialmente relevante, en este sentido, la comprensión implícita de las emociones como un proceso corporal. La emoción implica una conciencia de la cooperación corporal con una idea, un pensamiento o una actitud y la etiqueta adosada a esa conciencia (Hochschild, 2008). Sin embargo, la tendencia convencional es pensar las emociones como desvinculadas del cuerpo. Por tanto, la reconfiguración subjetiva, que aborda simultáneamente aspectos corporales y emocionales, resulta más eficaz para articular la experiencia del dolor y para establecer pautas de cuidado.

Gestión de los sentimientos, modulación del dolor

La expresión emocional, además de ser positiva en sí misma, nos sitúa en el nudo reflexivo de qué hace un sujeto con sus sentimientos. Las perspectivas psicosociales, según Hochschild (2008), han estado muy condicionadas por dos versiones contrapuestas del sujeto: por un lado, un yo cognitivo consciente; por otro, un yo emocional inconsciente. Este par de opuestos ha desdeñado el análisis de los sentimientos, tanto en su relación con las circunstancias 
sociales como en su relación con o entre procesos subjetivos. A pesar de que gran parte del desarrollo de estos procesos es inconsciente - no trasparente a la propia conciencia del sujeto-, los sentimientos adquieren su significado y carácter solo en relación con un tiempo y lugar específicos.

Todo contexto regula los sentimientos y esta regulación tiene una dimensión normativa - aquello que se considera apropiado o no-, una dimensión expresiva - aquello que se considera comunicable y que, en función de esta interacción, regula su falsedad o verdad — y una dimensión política — aquella que hace referencia a la dirección del sentimiento (Hochschild, 2008) -.

El desplazamiento de las reglas sociales en relación con los sentimientos permite la intensificación de prácticas imperceptibles - pero capacitadorasque compensan la limitación y el dolor ocasionados por la enfermedad, sin agotar la potencia subjetiva. El propio trabajo con los sentimientos, una vez problematizadas las normativas sociales al respecto, es muy reseñable.

De forma reflexiva y en infinidad de consejos, las participantes se dan, unas a otras, pautas de manejo de las emociones, lo cual abre la posibilidad de hacer algo con estas sin condenarlas al rechazo, a la soledad o a la desesperación ni a la falsa auto-regulación racional — como sucede con algunos prototipos, generalmente masculinos, de muchas narrativas sociales-. Atrapadas en su dolor y su agotamiento, saben y pueden operar táctica y sigilosamente sobre las emociones, para así producir pequeños cambios que las alivien. Conscientes de que serán inestables y frágiles, de que volverán las crisis y desesperaciones, articulan su batalla como un cuidado de sí que pasa por una regulación emocional. Aquí también, por tanto, encontramos indicadores de una agencia que se recompone y se comparte: "Soy la primera en creer y fomentar el buen ánimo, el optimismo y el equilibrio, como una forma de sobrellevar esta enfermedad que la tengo hace más de 35 años. Y creo que nos evita empeorar" (BF2, 68). "Así como yo estoy muy mal, trato de ponerle vida a mi vida y de seguir teniendo esperanza, por mí y por los míos" (BF2, 226).

\section{Atribuciones: causas y consecuencias}

Otro elemento que configura la agencia - en términos narrativos tanto como psicosociales - tiene que ver con la interpretación que establece relaciones diferentes entre causas y consecuencias. Las reordenaciones en la atribución de causalidad tienen importantes consecuencias afectivas y generan expectativas diferentes. Son, en ocasiones, decisivas para la construcción de culpabilidad.

Tengo hora con un reumatólogo y como el médico de la SS está de baja, voy a intentar que me hagan caso, y si no que me manden al psiquiatra, pero lo que no voy a hacer es seguir aguantando porque si no me voy a volver loca. (BF1, 27)

Respecto al psiquiatra o psicólogo te vendrá bien, no porque estés más o menos paranoica y veas más donde no lo hay, sino porque te ayudarán a superar una pérdida tan importante como es la nuestra. (BF1, 34)

Quién no se volvería loca, histérica, desequilibrada y no sé cuántas cosas más si después de un montón de años visitando médicos, especialistas de toda clase, haciéndonos toda clase de pruebas, para que te digan que no tienes nada. (BF1, 67)

También hay cierta comprensión de la enfermedad como curso vital, relacionada con otras experiencias vitales. Aunque no es lo más habitual, hay intervenciones que sitúan el inicio del dolor o el desencadenamiento de una crisis en una situación traumática, en una pérdida o en situaciones emocionales difíciles.

\section{Despliegue de estrategias: resubjetivación} frente a prácticas objetivantes institucionales

Uno de los ejes más interesantes del análisis lo constituye el intercambio de estrategias que está a la base de este proceso de resubjetivación colectiva. Las estrategias implican la adquisición de una posición activa — agencia - a partir de un saber compartido, que puede ser objeto de contraste, matización y experimentación. Esto configura el 
grupo como espacio de valoración y de percepción subjetiva en términos 'positivos'.

En algunos foros se asume de entrada, que no existe una cura para la fibromialgia y que, por lo tanto, no se la espera. Pero de ello no se deriva una actitud resignada ni apesadumbrada: "La aceptación de la enfermedad y mantener el ánimo alto y en positivo es lo que más nos ayuda. No tenemos cura pero sí buen humor y ganas de luchar. Un abrazo." (BF3, 77).

En la siguiente cita se puede apreciar el sentido compartido de los foros desde una dimensión más práctica y activa: "Cualquier novedad, por poco que parezca contarla, para que otras puedan probar, no todas reaccionamos igual, lo que a unas viene bien, a otras les viene mal, por eso debemos comunicarnos cualquier cosa que nos pueda ayudar. Besos." (BF1, 18).

Las personas que interactúan en el foro tienen la posibilidad de sentirse útiles, pues su propia experiencia ayuda a otras personas. Intercambian consejos de todo tipo, entre ellos, cómo afrontar la compleja relación con el dispositivo médico:

Decirte que si el médico de la SS está de baja, pongas una hoja de reclamaciones y solicites que ellos te manden a otro o solucionen tu problema que les das un plazo o tomarás otras medidas, contestan, te lo aseguro, yo soy la chica de las hojas de reclamaciones, no nos queda otra, para que no nos tomen el pelo. $(B F 1,33)$

Los consejos para el cuidado de una misma son los más abundantes: "Esto se puede llevar con cariño hacia ti misma y rodeándote de personas que te quieran, no te enfades por nada, es mejor que lo ignores" (BF1, 54). "De sobra sé que decir 'ianímate!' no es suficiente, pues de no hacerlo nos quedaríamos acostadas todo el día. Alimenta tu conciencia, trabaja otros aspectos de tu vida y algo bueno saldrá. Te lo aseguro" (BF2, 385).

Este tipo de consejos parten de la aceptación de la enfermedad como un proceso lleno de altibajos, donde más vale saberse cuidar a una misma para sobrellevarlo de la mejor manera:
"Pero tienes que encontrar la manera de controlar los síntomas de la enfermedad... así, el día que te encuentras bien pues haces lo que más te guste y los días menos buenos... pues se reposa aceptando que ya vendrán días mejores" $(\mathrm{BF} 3,8)$.

Los consejos se dirigen, en general, a la búsqueda de una práctica de cuidado que pueda complementar o sustituir las recetas médicas. Uno de los elementos asociados a este cuidado es practicar un equilibrio entre el esfuerzo corporal y el subjetivo:

Hay que comenzar creando una rutina diaria en donde realices todos los días diferentes labores y por lapsos de tiempo iguales, claro que siempre haciendo muchas pausas, como me dijo mi fisioterapeuta. Hay que sacar las palabras 'mucho', 'demasiado' y todos sus sinónimos de nuestras vidas. (BF4, 47)

\section{Conclusiones y discusión}

Partimos de los conceptos de biopoder y medicalización de la experiencia, articulándolos con el enfoque de género en salud (Velasco, 2009). Desde allí, nos preguntamos si los foros virtuales facilitan $-\mathrm{y}$ de qué manera- procesos de agenciamiento que, a su vez, generen transformaciones corporales, subjetivas, sociales y políticas significativas en la experiencia de dolor sin causa orgánica de mujeres diagnosticadas clínicamente con fibromialgia. A la luz del análisis cualitativo de las interacciones que estas mujeres sostienen en las plataformas en línea, surgieron tres ejes relativos a los procesos abiertos en la interacción virtual: a) dolor y búsqueda de sentido, b) resignificación subjetiva y c) construcción dialógica de la agencia. A partir de ellos, pudimos constatar diversidad de elementos asociados a una experiencia conflictiva, vinculada a su vez a una posición de género femenina normativa y subalterna. Esta experiencia es performada de maneras particulares por las mujeres que participan de los foros, desde sus experiencias específicas de dolor. Entre ellas, las más recurrentes fueron el malestar por la ausencia de sentido del dolor y por la falta de reconocimiento del mismo 
por parte de los 'otros' - especialmente cuando no es posible cumplir con las expectativas sociales proyectadas_-; la denuncia y el desconcierto por la psicopatologización y estigmatización social y médica; los usos de metáforas como "batalla" y "lucha" - relacionadas con las dificultades de quienes ocupan una posición vulnerable y subalterna-; la expresión ambivalente de rabia y enfado — paralelas a la culpa - y la tensión que genera la dificultad para el cuidado de otras personas.

Por otra parte $-\mathrm{y}$ en relación con la experiencia conflictiva-, surge otro conjunto significativo de elementos, asociados esta vez a una posición de agencia en la que es posible simbolizar la experiencia de las mujeres en unos términos similares a los que plantea Velasco (2009): la expresión de la necesidad y deseo de hablar con iguales para poder partir de la experiencia y voz propias en la construcción de un sentido del dolor; la posibilidad de reconocerse mutuamente en la narración de experiencias similares entre sí, que inauguran un saber no-biomédico sobre el dolor. Asimismo, surge una crítica al lenguaje de la autoridad, una valoración colectiva y la aceptación del propio cuerpo como parte integrada del yo. También se hace evidente la necesidad de expresión —y de regulación- emocional, una reducción de la autocrítica y la emergencia de una crítica orientada al exterior. Finalmente, se da una construcción conjunta de prácticas de autocuidado y de resistencia.

A través del análisis, constatamos que las experiencias conflictivas de estas mujeres habían sido enmudecidas por la "caja negra" de la categoría/diagnóstico clínico "fibromialgia", como consecuencia de los métodos e instrumentos al servicio del modelo hegemónico de salud: el biomédico. Este modelo se basa en una idea de sujeto dicotómico, dividido en mente y cuerpo, y se centra exclusivamente en este último, representándolo como un organismo y desestimando sus interacciones dinámicas con las otras partes del sujeto, como la subjetiva, la social y la cultural. Dicho modelo hegemónico de salud, además, se basa en una idea de sujeto universal 'neutro': un sujeto androcéntrico.
Sin embargo, y aunque partimos de la idea de que socializar el malestar puede convertirse en un motor para la movilización colectiva, vemos que este tipo de plataformas, al menos en sus primeras fases, se quedan cortas a la hora de facilitar un empoderamiento a nivel colectivo y de aumentar la participación en el espacio de lo público en relación con la igualdad y diversidad género. Y aunque, como plantea Lagarde (2005), ambos procesos de agenciamiento están muy relacionados entre sí, se necesitaría un estudio más longitudinal para poder valorar el potencial de agenciamiento colectivo de dichos foros — más allá de su potencial de transformación subjetiva-.

Otro aspecto significativo que se desprende del análisis es la función paradójica que juega el diagnóstico clínico de FM, ya que, por una parte, aporta un relativo reconocimiento social al dolor y a la persona que lo sufre, pero, por otra, la priva de un sentido experiencial, emocional, colectivo y cultural de su dolor. Esta ausencia de sentido impide la simbolización del malestar y, por tanto, bloquea el agenciamiento y el cambio subjetivos. Estos últimos, en contraste, sí son posibilitados por el uso que estas mujeres hacen de los foros en línea, donde las personas afectadas son desplazadas al centro de su narración, a través del reconocimiento intersubjetivo y del diálogo entre iguales. Dicho desplazamiento estaría asociado, además, a la expresión de una reducción — por mínima que sea- del malestar corporal y subjetivo.

Para acabar, queremos subrayar la relevancia y urgencia de abordar el concepto de salud/ bienestar dentro de un marco dialógico transdisciplinar en el que confluyan las ciencias sociales y humanas y las ciencias biomédicas: un marco capaz de sacar de la "caja negra" de las categorías diagnósticas clínicas a la experiencia conflictiva, subjetiva, social y política contemporánea de la FM, con el fin de posibilitar su simbolización. Dicho proceso de simbolización es clave para la transformación del malestar y el agenciamiento subjetivo (Velasco, 2009). Se trata, en definitiva, de un cambio de marco que permita transitar del dolor de las palabras (hegemónicas) a las palabras (transgresoras) del dolor. 


\section{Referencias}

Amigot, P. (2005). Relaciones de poder, espacio subjetivo y prácticas de libertad: análisis de un proceso intersubjetivo de transformación de género. (Tesis Doctoral). Departamento de Psicología de la Salud y Psicología Social. Universidad Autónoma de Barcelona.

Barker, K. (2005). Fibromialgya history. Medical authority and women's worlds of pain. Philadelphia: Temple University Press.

Bourdieu, P. (1982). Ce que parler veut dire. Paris: Fayard.

Carrasco Acosta, M. C., \& Garrido, M. (septiembre, 2008). El valor afectivo simbólico de los foros de fibromialgia. Antropología de la medicina, metodologías e interdisciplinariedad: De las teorías a las prácticas académicas y profesionales. XI Congreso de Antropología: retos teóricos y nuevas prácticas. Donostia.

Crespo, E. (1995). Introducción a la Psicología Social. Madrid: Universitas.

De Vogli, R. (2011) Neoliberal globalisation and health in a time of economic crisis. Social Theory and Health, 9(4), 311-325.

Foucault, M. (2007). Seguridad, territorio, población. Curso en el Collège de France (1977-1978). Buenos Aires: Fondo de Cultura Económica.

Hochschild, A. R. (2008). La mercantilización de la vida intima. Apuntes de la casa y el trabajo. Madrid: Katz.

Ibáñez, T. (2003). El giro lingüístico. En L. Iñíguez (Ed.), Análisis del discurso. Manual para las ciencias sociales. Barcelona: Editorial UOC.

Iñiguez, L. (2003). Análisis del discurso. Manual para las Ciencias Sociales. Barcelona: Editorial UOC.

Lagarde, M. (2005). Para mis socias de la vida. Madrid: Horas y Horas.

Luz, T. M. (2011). El desafío de la salud en las ciencias sociales: el caso de Brasil. Política y Sociedad, 48(2), $313-327$

Mora, E. (2005). Patriarcado, capitalismo y clases sociales, En J. Giró (Ed.), El género quebrantado. Sobre la violencia, la libertad y los derechos de la mujer en el nuevo milenio (pp. 143-181). Madrid: La Catarata.

Organización Mundial de la Salud (1992). Quitner, International Statistical Classification of Diseases and Related Problems. ICD-10. WHO, Geneve.
Pennebaker J. W., \& Graybeal A. (2001). Patterns of natural language use: Disclosure, personality and social integration. Current directions, 10, 90-93.

Potter, J., \& Wetherell, M. (1987). Discourse and social psychology: Beyond attitudes and behavior. Londres: Sage.

Pujal i Llombart, M.(2010). El binarismo de género como dispositivo de poder social, corporal y subjetivo. Quaderns de Psicología. 12(2), 131-148.

Pujal i Llombart, M., \& Mora, E. (2013). Trabajo, dolor y su diagnóstico psicosocial de género. Un ejemplo. Universitas Psychologica, 12(4), 1181-1193.

Pujal i Llombart, M., \& Mora, E. (2014). Subjetividad, salud y género: una aproximación al dolor cronificado mediante la metodología del Diagnóstico Psicosocial de Género. Estudios de Psicologia, 35(2), 212-238.

Rabeharisoa, V. (2006). From representation to mediation: The shaping of collective mobilization on muscular dystrophy in France. Social Science EO Medicine, 63, 564-576.

Ricoeur, P. (2001). La metáfora viva (2ª ed.). Madrid: Cristiandad.

Rivera, J. (2009). Tratamiento farmacológico en fibromialgia. V Jornadas Codo con Codo. Madrid: Fundación FF. Recuperado de http://www.laff.es/pdf/ CcC_tot_resum.pdf.

Rubin, G. (1986). El tráfico de las mujeres: notas sobre la economía política del sexo. Nueva Antropología, 8 (20), 95-145.

Spivak, G. (2003). ¿Puede hablar el sujeto subalterno? Revista Colombiana de Antropología. Vol. 39, 297-364.

Suriá, R., \& Beléndez, M. (2009). El efecto terapéutico de los grupos virtuales para pacientes con enfermedades crónicas. Boletín de Psicología, 96, 35-46.

Tajfel, H. (1978). Differentiation between social groups: Studies in the social psychology of intergroups relations. London: Academic Press.

Taylor, S. J., \& Bogdan, R. (2000). Introducción a los métodos cualitativos de investigación. La búsqueda de significados. Barcelona: Paidós.

Turner, J. C. (1987). Rediscovering the social group: A selfcategorization theory. Oxford: Blackwell.

Ubago, M. C., Ruiz, I., Bermejo, M. J., de Labry, A., \& Plaza, J. (2005). Características clínicas y psicoso- 
ciales de personas con fibromialgia. Repercusión del diagnóstico sobre sus actividades. Revista Española de Salud Pública, 79 (6), 683-695.

Velasco, S. (2009). Sexos, Género y Salud. Madrid: Minerva.

Velasco, S., Lopez, B., Tourné, M., Caldero, M .D., Barcelo, I., \& Luna, C. (2007). Evaluación de una intervención biopsicosocial para el malestar de mujeres en atención primaria. Feminismos, 10, 111-131.
Walther, J. B., \& Parks, M. R. (2002). Cues filtered out, cues filtered in: Computer mediated communication and relationships. En M. L. Knapp \& J. A. Daly (Eds.), Handbook of interpersonal communication (pp. 529-563). Thousand Oaks, CA: Sage.

Wittgenstein, L. (1969). Cuadernos azul y marrón. Madrid: Tecnos. 1993 
